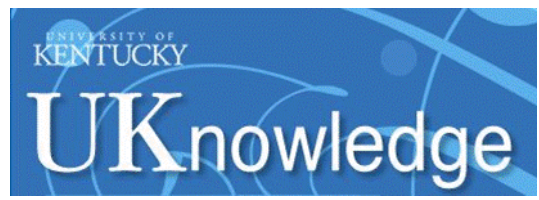

University of Kentucky

UKnowledge

\title{
Barriers and Facilitators of Parent Engagement with Health Promotion in Child Care: A Mixed-Methods Evaluation
}

\author{
Courtney T. Luecking \\ University of Kentucky, courtney.luecking@uky.edu \\ Phillip Dobson \\ University of North Carolina at Chapel Hill \\ Dianne S. Ward \\ University of North Carolina at Chapel Hill
}

Follow this and additional works at: https://uknowledge.uky.edu/foodsci_facpub

Part of the Dietetics and Clinical Nutrition Commons

Right click to open a feedback form in a new tab to let us know how this document benefits you.

\section{Repository Citation}

Luecking, Courtney T.; Dobson, Phillip; and Ward, Dianne S., "Barriers and Facilitators of Parent Engagement with Health Promotion in Child Care: A Mixed-Methods Evaluation" (2020). Dietetics and Human Nutrition Faculty Publications. 22.

https://uknowledge.uky.edu/foodsci_facpub/22

This Article is brought to you for free and open access by the Dietetics and Human Nutrition at UKnowledge. It has been accepted for inclusion in Dietetics and Human Nutrition Faculty Publications by an authorized administrator of UKnowledge. For more information, please contact UKnowledge@lsv.uky.edu. 


\title{
Barriers and Facilitators of Parent Engagement with Health Promotion in Child Care: A Mixed-Methods Evaluation
}

\author{
Digital Object Identifier (DOI) \\ https://doi.org/10.1177/1090198120952040 \\ Notes/Citation Information \\ Published in Health Education \& Behavior. \\ (C) 2020 Society for Public Health Education
}

The copyright holder has granted the permission for posting the article here.

The document available for download is the authors' post-peer-review final draft of the article. 
Title: Barriers and Facilitators of Parent Engagement with Health Promotion in Child Care: A Mixed Methods Evaluation

Authors: Courtney T Luecking, $\mathrm{PhD}^{1}$, Phillip Dobson, $\mathrm{BSPH}^{2}$, Dianne S Ward, EdD ${ }^{2,3}$

${ }^{1}$ Department of Dietetics and Human Nutrition, College of Agriculture, Food and

Environment, University of Kentucky

${ }^{2}$ Center for Health Promotion and Disease Prevention, University of North Carolina at Chapel Hill

${ }^{3}$ Department of Nutrition, University of North Carolina at Chapel Hill

\section{Corresponding author:}

Courtney T Luecking

University of Kentucky, Department of Dietetics and Human Nutrition, 206F Funkhouser

Building, Lexington, KY 40506-0064

Telephone number: (829)-257-9047

Fax number: $\mathrm{n} / \mathrm{a}$

E-mail: $\underline{\text { Courtney.luecking@uky.edu }}$

Acknowledgements: We like to thank Rachel Bartlett, Mikayla Bowen, and Rachel Banawa for their contributions to identifying the sample for this study, transcribing interviews, and data analysis. We are grateful for the guidance from Paul Mihas and Lorin Bruckner at the Odom Institute at the University of North Carolina at Chapel Hill regarding mixed methods and data visualization software. We would also like to thank Dr. Alice Ammerman, Dr. Kimberly 
Truesdale, Dr. Byron Powell, and Dr. Deborah Tate for their review of early versions of this manuscript. Finally, we would like to thank the early care and education providers and parents who volunteered their time for this project.

Funding Information: The National Heart, Lung, and Blood Institute of the National Institutes of Health (R01HL120969) supported this work. The project was conducted out of the University of North Carolina at Chapel Hill at the Center for Health Promotion and Disease Prevention, a Prevention Research Center funded through a cooperative agreement with the Centers for Disease Control and Prevention (1U48DP005017). Findings and conclusions of this article are those of the authors and do not necessarily represent the official position of the National Institutes of Health, National Heart, Lung, and Blood Institute or Centers for Disease Control and Prevention. The sponsor had no role in the study design; collection, analysis, or interpretation of the data; writing of the article; or decision to publish this article.

\section{Declaration of Conflicting Interests:}

The authors declare no conflict of interest. 
Title: Barriers and Facilitators of Parent Engagement with Health Promotion in Child Care: A Mixed Methods Evaluation

\begin{abstract}
:
Background. Early care and education (ECE) providers cite lack of parent engagement as a central barrier to promoting healthy behaviors among young children. However, little research exists about factors influencing parent engagement with promoting healthy eating and activity behaviors in the ECE setting.
\end{abstract}

Aims. This study aimed to address this gap by examining low and high parent engagement with the Healthy Me, Healthy We (HMHW) campaign to identify barriers and facilitators of parent engagement with the intervention.

Methods. This comparative case study used an explanatory sequential mixed methods approach. We created center-level parent engagement scores using process evaluation data from the effectiveness trial of HMHW. Recruitment focused on centers with the five lowest and five highest scores. Twenty-eight adults ( $n=7$ directors, $n=9$ teachers, $n=12$ parents) from seven centers ( $n=3$ low engagement, $n=4$ high engagement) completed semi-structured interviews and the Family and Provider/Teacher Relationship Quality measure. Analytic approaches included descriptive statistical analyses for surveys and a framework-informed thematic analysis for interviews.

Results. Prominent contrasts between low and high engagement groups involved center culture for parent engagement and health promotion, practices for fostering networks and communication within centers, and communication between centers and parents. Personal 
attributes of providers (e.g., attitudes) also differentially influenced practices for engaging parents.

Discussion and Conclusion. Organizational characteristics and individual practices can facilitate or impede parent engagement with health promotion efforts. Assessing organizational context, gaining input from all stakeholders, and conducting capacity-building interventions may be critical for laying the foundation for positive relationships that support parent engagement in implementation of health promotion programs and beyond.

Keywords: family; early care and education; nutrition; physical activity; implementation; mixed methods 


\section{Introduction}

Dietary and physical activity behaviors in early childhood create a foundation for shortand long-term growth, development, habits, academic achievement, and overall health (Birch \& Fisher, 1998; Institute of Medicine, 2000; Janz, Dawson, \& Mahoney, 2000). However, a majority of young children do not meet recommendations for healthy lifestyle patterns (Beets, Bornstein, Dowda, \& Pate, 2011; Fox et al., 2016). Parents or other adults who serve as primary caregivers have significant influence on young children's behaviors (Savage, Fisher, \& Birch, 2007; Zecevic, Tremblay, Lovsin, \& Michel, 2010). Yet, approximately one in three children under age six spends an average of 30 hours per week in early care and education (ECE) settings (i.e., preschool, child care, day care) (Corcoran, Steinley, \& Grady, 2016). Therefore, ECE providers also have significant influence on children's dietary and physical activity behaviors (Larson, Ward, Neelon, \& Story, 2011). For the more than seven million children who attend ECE settings in the United States, synergy among parents and ECE providers is essential for supporting the development of healthy behaviors (Nixon et al., 2012; Ward et al., 2017). However, ECE providers often cite lack of parent engagement as a central barrier to promoting healthier habits among children (Chow \& Humbert, 2011; Lyn, Evers, Davis, Maalouf, \& Griffin, 2014; Taveras, LaPelle, Gupta, \& Finkelstein, 2006).

Limited research is available regarding barriers or facilitators for parent engagement with health promotion efforts in ECE settings (Dev et al., 2017; Jayasuriya, Williams, Edwards, \& Tandon, 2016; Johnson et al., 2013; Taveras et al., 2006). Communication about children's nutrition or eating behaviors is a significant barrier to parent engagement (Dev et al., 2017; Johnson et al., 2013). ECE providers are unsure whether parents are interested in nutrition education, how to communicate without offending parents and feel time is a limiting factor. 
Jayasuriya et al. (2016) reported potential barriers in communication regarding outdoor play in that parents generally support outdoor play but were uninformed about outdoor playtime or related policies. Finally, in planning for health promotion efforts in ECE settings serving families with limited resources, Taveras et al. (2006) identified potential barriers related to ECE providers' perceptions of parents' attitudes about health promotion, whether ECE providers felt it was their role to lead health promotion activities, and concerns about language, literacy, and cultural barriers.

Previous investigations have identified barriers for narrow topics, and no inquiries have applied determinant or practical frameworks to evaluate contextual factors influencing parent engagement around health promotion. Determinant frameworks include classes of factors hypothesized or found to impede or facilitate implementation outcomes, whereas practical frameworks offer a "how-to" guide (Nilsen, 2015). This presents an important gap in that frameworks yield more thorough investigation and findings can contribute to a broader evidence base (Gardner, Whittington, McAteer, Eccles, \& Michie, 2010). Additionally, application of these types of frameworks could facilitate translation of research to practice. Finally, investigations to barriers typically occur prior to the development or implementation of an intervention to gain insight to what people think they need or want (Taveras et al., 2006). While an important part of the planning process (Bartholomew, Parcel, \& Kok, 1998), much could be learned about what works and what could be done differently by exploring barriers and facilitators actually experienced during implementation of ECE center-based health promotion programs (Dehar, Casswell, \& Duignan, 1993). However, to the authors' knowledge, no such research has been conducted. 
Healthy Me, Healthy We (HMHW) is an 8-month social marketing campaign designed to improve the diet quality and increase minutes of physical activity of 3-4-year old children attending ECE centers (Hennink-Kaminski et al., 2018). The HMHW campaign included kickoff and celebration events as well as four units of branded educational materials and activities designed to help ECE providers and parents partner to promote healthier behaviors for children at the ECE center and at home (Vaughn, Bartlett, Luecking, Hennink-Kaminski, \& Ward, 2018). Despite efforts to facilitate partnerships for health promotion, ECE providers offered mixed feedback about whether desired levels of parent engagement were achieved. These diverse impressions about the campaign presented a pragmatic opportunity to explore experiences of those who achieved higher levels of parent engagement and those who had lower engagement (Creswell, 2014). The purpose of this mixed methods study was to: 1) identify extreme cases of low and high parent engagement with HMHW using quantitative process evaluation data from the cluster randomized control trial and 2) characterize barriers and facilitators of parent engagement based on qualitative interviews and quantitative surveys with ECE directors, teachers, and parents affiliated with the extreme cases.

\section{Methods}

\section{Study Design}

This comparative case study used an explanatory sequential mixed methods approach (quan $\rightarrow$ QUAL + QUAN) (Creswell \& Plano Clark, 2011) to identify and subsequently compare and contrast ECE centers that demonstrated low or high parent engagement within the HMHW campaign. This approach was selected based on the underlying principles of synergy from combining quantitative and qualitative methods and the ability to triangulate findings and elaborate on notable discrepancies between low and high engagement cases (Creswell \& Plano 
Clark, 2011; Palinkas et al., 2011; Wensing \& Grol, 2005). Reporting is in accordance with the Journal Article Reporting Standards for mixed method research (Levitt et al., 2018).

To identify ECE centers eligible for this study, process evaluation data from the second of two waves of a cluster randomized control trial evaluating the effect of HMHW (HenninkKaminski et al., 2018) were used to create a center-level, quantitative indicator of parent engagement with the campaign. Data collection occurred in suburban and rural settings in central North Carolina of the United States during the 2016 - 2017 school year. After parent engagement scores were generated, an extreme case, purposeful sampling approach (Palinkas et al., 2015) was used to identify and recruit a total of 10 ECE centers that demonstrated the five lowest and five highest scores of parent engagement. The goal was to have at least three low engagement and three high engagement centers participate (Guest, Bunce, \& Johnson, 2006).

Directors were contacted via phone and e-mail. Once they expressed interest, they facilitated connection with teachers and parents who participated in HMHW. Directors, teachers, and parents completed quantitative and qualitative measures. Surveys collected information about the quality of relationships between ECE providers and parents as well as demographic characteristics. All participants completed a semi-structured interview with a single, experienced member of the research team regarding the context of their experience collaborating to promote healthy habits through the HMHW campaign. Recruitment and data collection occurred in July and August 2017. Participants received \$30 compensation for time and effort to complete all measures. The Institutional Review Board at the University approved all study protocols.

\section{Data Collection/Measures}

\section{Quantitative.}


Parent Engagement. We developed a 53-item indicator of parent engagement (Table 1) based on previously collected process evaluation data (Hennink-Kaminski et al., 2018). Items were pulled from multiple sources and represented distinct perspectives - data collectors, directors, teachers, parents, and study interventionist - to create a single, inclusive assessment of parent engagement with HMHW. Seven items from the Environment and Policy Assessment and Observation (EPAO) document review tool, shown to have strong inter-observer agreement, 79.29\% (SD=7.43), (Ward et al., 2008) captured centers' policies and structured practices regarding parent engagement around health promotion. Fifteen items from director and teacher responses to structured interview questions captured implementation of the intervention. Twenty items from parent surveys captured exposure to and implementation of intervention materials. Lastly, the study's interventionist completed an 11-item survey regarding organizational context that would theoretically influence implementation at the ECE center and parent engagement with the campaign (e.g., staff expressing heavy workloads). Items demonstrated good internal consistency (Cronbach's alpha $=0.8$ ) and were summed to create a center-level score (possible range $11-139)$.

Relationship Quality. The Family and Provider/Teacher Relationship Quality (FPTRQ) measure (Kim et al., 2015) was selected to triangulate results from interviews and evaluate the construct validity of the parent engagement indicator. The FPTRQ takes less than 10 minutes to complete, is designed for use across different types of ECE centers for children birth to 5 years of age and captures the perspective of both parents and providers regarding important elements of parent-provider relationships. The director survey (23 items, response range $0-17)$ measures environmental features regarding atmosphere, organizational climate, and resources for families. The teacher (16 items with subcomponents, response range 51 - 204) and parent (19 items with 
subcomponents, response range 66 - 264) surveys measure dimensions of professional practice, including knowledge about families, attitudes, and practices surrounding parent-provider interactions. The FPTRQ includes constructs theoretically relevant to parent engagement (i.e., practices surrounding parent-provider interactions) and has demonstrated good to excellent internal reliability (Cronbach’s alpha range: 0.63 - 0.97) (Kim et al., 2015).

Qualitative. Two frameworks, the Consolidated Framework for Implementation Research (CFIR) (Damschroder et al., 2009) and Epstein's framework for school-familycommunity partnerships (Epstein, 2010), were used to structure interview guides and exploration into underlying approaches to parent engagement. The CFIR is a determinant framework that provides pragmatic structure for identification of complex, multilevel factors influencing implementation of interventions. For this study, emphasis was placed on identification of barriers and facilitators of the organizational context (e.g., culture, implementation climate) within which HMHW was implemented (i.e., the inner setting) and the strategies and tactics (e.g., planning, executing) to implement HMHW (i.e., implementation process). The Epstein framework is a practical framework that provides guidance for developing partnerships between educational organizations and families. Specifically, the framework identifies six types of involvement and suggested practices - parenting, communicating, volunteering, learning at home, decisionmaking, and collaborating with community. Application of these frameworks would allow for identification of contextual and practical elements that impede or facilitate parent engagement with health promotion.

The principal investigator (PI) developed separate yet similar interview guides for directors, teachers, and parents. Director interview guides were based on the CFIR and developed using the associated interview guide tool (The Consolidated Framework for 
Implementation Research, n.d.). Questions focused on inner setting constructs regarding structural characteristics, organizational culture, implementation climate, and networks and communication, as well as process constructs related to the planning and execution of HMHW, the involvement of key stakeholders, and reflection and evaluation on the process. Parent interview guides included questions to explore whether or how the six elements of Epstein's framework were used to promote parent engagement, and teacher interview guides were a hybrid of director and parent guides. Interview guides were reviewed by members of the research team specializing in ECE and implementation science, pilot tested with directors, teachers, and parents who participated in wave one of the randomized trial, and modified to reduce the length and improve clarity. The study PI, an experienced researcher, conducted all semi-structured interviews over the telephone. Interviews lasted an average of 55 minutes (range $34-87$ minutes). Interviews were audio recorded for later transcription by members of the research team.

\section{Analysis}

Quantitative. Descriptive statistical analyses were conducted for all quantitative measures. Pearson correlation was used to evaluate convergent validity of the parent engagement measure with the FPTRQ measure. All analyses were performed in SAS version 9.4 (SAS Institute, Inc., Cary, NC).

Qualitative. Transcripts were analyzed in MAXQDA Analytics Pro - Student (VERBI Software, 2016, Berlin: Germany) software. Thematic analysis was conducted through iterative cycles of applying deductively and inductively derived codes to segments of text in response to interview questions (Saldaña, 2013). The initial coding framework included deductively defined constructs from the CFIR and Epstein frameworks used to develop interview guides and general 
barrier and facilitator codes that were further specified through an inductive process. The analysis team included the PI, experienced in qualitative research, and two research assistants trained by the PI. After training, each member of the analysis team independently coded three interviews - one director, one teacher, and one parent. The team met to review consistency, discuss discrepancies or uncertainties about applying codes, and identify deficiencies in the current coding framework. To enhance rigor, the PI and a research assistant independently coded each transcript. Kappa coefficients were generated for each interview by MAXQDA Analytics Pro - Student. The research team demonstrated moderate inter-rater reliability (kappa $>0.7$ ) by the fifth interview (McHugh, 2012). The analysis team continued to meet regularly to review consistency and accuracy of applying codes, to reconcile discrepancies, and to revise the codebook as needed. This led to modification of codes to clarify pre-specified constructs and create new codes to capture sub-themes within the original constructs (e.g., barrier - time, family characteristics) (Saldaña, 2013).

Survey results were imported to MAXQDA Analytics Pro - Student. To facilitate organization and interpretation of data across low and high cases, matrices of survey and thematic data were generated based upon parent engagement group (Yin, 2009). The PI wrote memos to summarize each matrix. Memos included demonstrative quotes and numerical data to highlight similarities and differences of data sources within cases (e.g., low engagement group), participant roles (i.e., parent, teacher, director), and across low and high cases. The research team met to review memos and come to consensus about organization, interpretation, and implication of findings.

\section{Results}

\section{Identification of Extreme Cases of Parent Engagement}


Parent engagement scores. Eligible ECE centers had an average parent engagement score of $69.3 \pm 11.7$ (range $47-104$ ) points. Centers invited to this study included those with the five lowest (range $47-58$ ) and five highest scores (range $82-104)$. Pearson correlations between the center-level parent engagement scores and FPTRQ Total scores $(\mathrm{r}(15)=0.49$, $\mathrm{p}=0.054)$ and theoretically relevant FPTRQ Practices construct $(\mathrm{r}(15)=0.55, \mathrm{p}=0.03)$, provide moderately positive, statistically significant support that the parent engagement score appropriately identified extreme cases of parent engagement.

Participants. Seven centers agreed to participate - three representing low engagement and four representing high engagement (Table 2). There were no differences in demographic characteristics between groups. ECE programs represented prekindergarten, Head Start, and faith-based organizations. All programs accepted childcare subsidies and participated in the Child and Adult Care Food Program, indicating at least 25\% of families within each center qualified for free or reduced-price meals. Only one center, a low engagement center, had national accreditation signifying a high quality ECE program. More high engagement than low engagement programs used health promotion curriculum. Among these centers, seven directors, nine teachers, and 12 parents consented to participate (Table 3). Most of this sample identified as female (96\%), African American or black (86\%), having less than a college degree (64\%), and an annual family household income less than $\$ 60,000(57 \%)$.

\section{Barriers and Facilitators of Parent Engagement}

There were notable differences between the low and high engagement groups regarding center culture for parent engagement and health promotion and networks and communications (i.e., communication amongst ECE providers), both inner setting constructs of CFIR. There were also differences regarding approaches for communicating (i.e., between ECE programs and 
home) and parenting (i.e., supporting healthy habits at home), constructs from Epstein's

framework. Although not explicitly asked about, knowledge, beliefs and other personal attributes (i.e., CFIR constructs for characteristics of individuals) were identified as important factors that facilitate or impede parent engagement. Table 4 depicts an overview of differences and demonstrative quotes.

\section{Organizational Context (i.e., Inner Setting from CFIR)}

Center culture. Providers at high engagement centers consistently alluded to a priority of teamwork with parents - "We really see ourselves all connected in a school family. So every family... wherever that family structure is, that the family is also part of the school" (director, high engagement). However, except for one teacher, this sentiment was absent from the low engagement group. High engagement centers unanimously discussed the priority of actively working towards building rapport and relationships with parents as a way to promote children's development through parent engagement - "If you have parent rapport, if you have a good relationship with your parents, then it will be much easier to implement anything you wanna implement" (director). In contrast, the low engagement group expressed tension between wanting to implement new programs to support parent engagement and feeling previous attempts to eliminate perceived barriers to participation (e.g., food, incentives, child care, transportation) have failed - "You know we always need to get the parents involved more. But I feel like, we kind of do the best we can" (director).

Networks \& communication. Director FPTRQ scores suggest the low engagement group (16 \pm 1.0$)$ slightly surpassed the high engagement group $(14.3 \pm 2.2)$ in efforts to create a welcoming environment that supports families and the formation of strong relationships. However, parents in the low engagement group expressed desire for providers to "communicate 
a little more amongst each other so they can communicate better with parents." Parents felt there was insufficient transition of information between shifts and/or differing expectations or roles for different teachers, particularly when afternoon teachers seemed uninformed about HMHW.

\section{Parent Engagement Practices (i.e., Types of Involvement from Epstein's Framework)}

Communicating. Caregivers consistently stated "communication is key" to parent engagement. However, parents in both groups had inconsistent feelings about the need to communicate about children's eating or physical activity behaviors, thus confirming some providers' perceptions that parents are not interested in these topics. Some felt it was helpful to learn about foods children ate at the center, but others felt either "it wouldn't be one of the things where I might need to talk to the teacher" (low engagement) or "truthfully I guess that's something (physical activity) that I'm not too concerned about at the moment" (high engagement).

Communication subscale scores from the FPTRQ Practices construct (Figure 1) indicate differences in approaches to foster bidirectional communication. Remarkably, instead of thinking about communication as an opportunity for ongoing, two-way interactions, it was often described as one-way delivery of information. The low engagement group spoke more about providing reminders or general updates, and providers acknowledged they were less direct in asking parents to be involved - "But I will say we didn't ask for any parents to volunteer" (teacher). The high engagement group spoke more about candid interactions regarding (re)evaluating children's progress, direct invitations to participate, or specific requests for support. They also communicated in a manner that let parents know, "we sure would like to have you involved" (director). While parents in both groups felt like their voices are heard - "we come in with concerns or a problem and they take care of it" (low engagement) - communication is often in 
response to problems, not an ongoing process that involves positive feedback or general suggestions.

Parenting. Parents need to feel empowered and have confidence about their role in supporting healthy behaviors at home, but groups described different approaches for this. Every participant in the high engagement group provided examples of support to achieve healthier habits at home (e.g., connection to resources, encouragement to "do better"). Whereas, most providers at low engagement centers acknowledged "(laugh) I don't think we do anything for that connection" (teacher). Parents at low engagement centers confirmed, "these are the types of conversations that have never been had," thus emphasizing an important missed opportunity to enable parents to "do their part" at home.

\section{Attitudes and Capacity of ECE Providers to Engage Parents (i.e., Characteristics of Individuals from CFIR)}

Family-specific knowledge. The value providers place on the family as a unit, as opposed to the individual child, can influence the type of information they seek. Providers agreed, "you really have to tailor things" (director, low engagement), which often meant taking steps to meet parents where they are regarding language and level of education. However, scores consistently below the median reference for the Knowledge construct of the FPTRQ (Figure 1) indicate teachers and parents do not frequently share information about their needs, goals, or circumstances within which the family is living. Providers in the high engagement group reflected, "It's hard for us sometimes as teachers to realize that families are their (children's) primary influence, not us. And so, we need to know as much about them as we can and value and respect them" (director). In turn, they demonstrated the ability to personalize interactions with families based on their culture or home environment. Providers in the low engagement group did 
not share this sentiment and instead communicated a preference for focusing on children - "The children I love, it's the parents I can't do anything with" (teacher).

Other personal attributes of ECE providers. Teachers' attitudes about caring for children and working with families were more positive in the high engagement group than the low engagement group (Attitudes construct, Figure 1). Teachers in the high engagement group expressed "it can't be us against them" and gratitude for any time or commitment parents had to offer, even if it was not ideal. Contrary to these views, providers at every low engagement center felt disrespected, noting "they look at us as a babysitting service versus the people who are trying to do better about their kid" (teacher) and voiced exasperation about trying different things to get parents involved but feeling "it's still not working" (teacher). As such, they often interpreted parents' lack of participation as "you don't want to help me" (teacher) or a having a chip on their shoulder. A counter interpretation from the high engagement group is that there is a lack of trust or "we just haven't found the right connection yet" (teacher). Regardless, previous experiences have left teachers, particularly in the low engagement group, feeling depleted - "to be honest, I really don't want them to be involved because it's like a challenge all the time."

\section{Discussion}

This comparative case study utilized a mixed methods approach to identify extreme cases of parent engagement with the HMHW campaign and characterize barriers and facilitators of parent engagement. The juxtaposition of directors, teachers, and parents who had varying experiences and the application of frameworks led to the identification of organizational characteristics and individual practices that either facilitated or impeded parent engagement. The most prominent contrasts between low and high engagement groups included center culture for parent engagement and health promotion, practices for fostering networks and communication 
within ECE centers, and communication between ECE centers and parents. Additionally, personal attributes of ECE providers influenced practices for engaging parents.

The difference of high engagement centers striving to work with families and low engagement centers feeling like they work for families highlights the impact an organization's context has on the quality or degree of parent engagement. High engagement centers spoke of a culture that prioritized collaborating with parents and thinking "outside the box" to identify new or different ways for families to be involved. Low engagement centers spoke of feeling like a "babysitting service" and wanting more parent engagement, yet examples of efforts to involve parents comprised one-way delivery of information rather than invitations or actions to promote collaboration. Similarly, previous research into the quality of partnerships between family and ECE providers evaluated through an organizational systems lens suggest key factors for supporting high quality engagement. These include priorities of teamwork from front-line staff and administrators and an overarching culture that values and supports creating and sustaining caring and responsive relationships (Douglass, 2011). A lack of structure and processes to support relationships and shared power between ECE providers and parents could be an important barrier to address to support parent engagement with health promotion and more broadly.

ECE providers frequently state lack of parent engagement hinders building healthier habits (Chow \& Humbert, 2011; Lyn, Evers, Davis, Maalouf, \& Griffin, 2014; Taveras, LaPelle, Gupta, \& Finkelstein, 2006). Results from this study indicate organizational factors like turnover and communication amongst staff may be important influencers of parent engagement. Staff turnover is a recognized barrier to program implementation in ECE settings and beyond (Swindle et al., 2019). Results from the present study invite consideration of effects of turnover beyond 
program implementation. Staff turnover disrupts attachment between children and their ECE provider and creates additional stress for other staff (Hale-Jinks, Knopf, \& Knopf, 2006). It may also affect communication and relationship building processes that are fundamental for high quality parent engagement. Workforce development and administrative support may be important strategies for reducing staff turnover (Hale-Jinks et al., 2006; Swindle et al., 2019).

Previous inquiries of barriers to parent engagement with health promotion have yielded important insights about communication (Barnes, Guin, Allen, \& Jolly, 2016; Dev et al., 2017; Johnson et al., 2013). Similar to previous findings, ECE providers in this sample acknowledged they undertake a "trial and error" process to identify effective methods and styles of communication (Barnes et al., 2016). In addition, they expressed a range of comfort in talking about nutrition or physical activity (Dev et al., 2017; Johnson et al., 2013). Providers want to avoid offending parents or are unsure how to address general nutrition topics when parents are only interested if their child is experiencing specific food issues. In this study, parents' attitudes and priorities about healthy eating and physical activity varied, perhaps validating providers' concerns, but there were no stark contrasts between groups. Other studies have identified that parents' attitudes, personal habits, physical environments and limited time influence their ability to support healthy eating and physical activity at home and thus could affect parent engagement around these topics (Dwyer, Needham, Simpson, \& Heeney, 2008; Jarvis, Harrington, \& Manson, 2017). Relational practices that enable providers to learn about a family's culture, circumstances, goals, and values regarding health promotion can help providers frame messaging for these potentially uncomfortable topics (Slater et al., 2010). Communication is an essential element of parent engagement (Halgunseth et al., 2009) and ongoing professional development strategies, such as training and coaching, are needed to support ECE providers to 
engage in ongoing, positive, two-way communication that invites parents to participate (Forry, Moodie, Simkin, \& Rothenberg, 2011).

Responses from participants resoundingly identified an important gap in previous research and the frameworks used to structure these investigations. Relationships between ECE providers and parents were named a key precursor for parent engagement, suggesting processes that initiate and nurture these relationships are important for achieving the ultimate goal of engaging parents in health promotion or otherwise. In fact, strong partnerships between ECE providers and parents can build mutual trust (Karakuş \& Savaş, 2012) that facilitates candid conversations between caregivers, even for sensitive topics (Reedy \& McGrath, 2010). As such, more attention may be needed prior to implementing new health promotion activities (Walker, Mwaria, Coppola, \& Chen, 2014). Assessing organizational context, gaining input from all stakeholders, and conducting capacity-building interventions may be critical for laying the groundwork for implementing health promotion programs and successfully engaging parents in the process (Huynh et al., 2018; Leeman et al., 2015; Vaughn et al., 2019).

This study is not without limitations. Parent engagement scores were generated at a center-level using a measure created specifically for this intervention from process evaluation data. While the organization at-large influences approaches for parent engagement, individual teachers and classroom-level factors greatly influence parent engagement. Still, center-level parent engagement scores agreed with an existing measure about relationship quality between parents and teachers (Kim et al., 2015), suggesting the center-level score was adequate to identify extreme examples of parent engagement. Of additional consideration is the fact parents volunteered for this study, and the type of parents that frequently frustrate ECE providers may not be represented. Finally, the small sample size and context within which this study was 
conducted limits the generalizability of results. Evaluating a single health promotion intervention delivered through ECE centers in central North Carolina with a small sample of mostly female, African American individuals may not be applicable to other settings. In spite of these limitations, this study had several strengths. First, this study expanded upon previous investigations of barriers and facilitators by soliciting actual experiences of all stakeholders who recently completed a health promotion program designed to link ECE and home. This provided a concrete, less frequently reported, opportunity to identify what worked and what could be better (Dehar, Casswell, \& Duignan, 1993). Second, applying a comprehensive indicator of parent engagement with a health promotion intervention allowed for purposeful identification and comparison of ECE centers with different experiences. Finally, the application of two frameworks, one practical and one determinant, allowed for more thorough investigation and identification of barriers and facilitators for parent engagement that allows results to be evaluated beyond the ECE setting.

\section{Implications for research and practice}

The findings from this study indicate organizational characteristics and individual practices may facilitate or impede parent engagement with health promotion efforts. The underlying importance of relationships between ECE providers and parents holds important implications for research and practice. This is an understudied area and it is evident some ECE providers will need more support in developing positive partnerships. In order to develop solutions for increasing parent engagement, specifically with health promotion and more generally, the organizational context of ECE centers must be evaluated through views of all stakeholders (Douglass, 2011). Potential strategies identified in this study include policies and procedures to establish a culture that supports relationships and shared power and ongoing 
professional development for positive, two-way communication about health promotion.

Capacity-building interventions that respond to individual ECE center's needs may be critical for laying the foundation for positive relationships that support parent engagement in

implementation of health promotion programs and beyond, and the evaluation of the impact of such efforts is needed. 


\section{References}

Bartholomew, L. K., Parcel, G. S., \& Kok, G. (1998). Intervention mapping: A process for developing theory and evidence-based health education programs. Health Education \& Behavior, 25(5), 545-563. https://doi.org/10.1177/109019819802500502

Beets, M. W., Bornstein, D., Dowda, M., \& Pate, R. R. (2011). Compliance with national guidelines for physical activity in U.S. preschoolers: measurement and interpretation. Pediatrics, 127(4), 658-664. https://doi.org/10.1542/peds.2010-2021

Birch, L., \& Fisher, J. (1998). Development of eating behaviors among children and adolescents. Pediatrics, 101(Supplement 2), 539-549.

Chow, A. F., \& Humbert, L. (2011). Physical activity and nutrition in early years care centres: Barriers and facilitators. Journal of Childhood Studies, 36(1), 26-30. https://doi.org/10.18357/jcs.v36i1.15136

Corcoran, L., Steinley, K., \& Grady, S. (2016). Early Childhood Program Participation, Results from the National Household Education Surveys Program of 2016 (NCES 2017-101.REV), National Center for Education Statistics, Institute of Education Services, U.S. Department of Education. Washington, DC. Retrieved April 6, 2019 from https://nces.ed.gov/pubs2017/2017101REV.pdf

Creswell, J. W., \& Plano Clark, V. L. (2011). Designing and conducting mixed methods research (3rd ed.). SAGE Publications, Inc.

Damschroder, L. J., Aron, D. C., Keith, R. E., Kirsh, S. R., Alexander, J. A., \& Lowery, J. C. (2009). Fostering implementation of health services research findings into practice: a consolidated framework for advancing implementation science. Implementation Science, 4(1), 50. https://doi.org/10.1186/1748-5908-4-5 
Dehar, M.-A., Casswell, S., \& Duignan, P. (1993). Formative and process evaluation of health promotion and disease prevention programs. Evaluation Review, 17(2), 204-220. https://doi.org/10.1177/0193841X9301700205

Dev, D. A., Byrd-Williams, C., Ramsay, S., McBride, B., Srivastava, D., Murriel, A., ... AdachiMejia, A. M. (2017). Engaging parents to promote children's nutrition and health. American Journal of Health Promotion, 31(2), 153-162. https://doi.org/10.1177/0890117116685426

Douglass, A. (2011). Improving family engagement: The organizational context and its influence on partnering with parents in formal child care settings. Early Childhood Research and Practice, 13(2).

Dwyer, J., Needham, L., Simpson, J. R., \& Heeney, E. S. (2008). Parents report intrapersonal, interpersonal, and environmental barriers to supporting healthy eating and physical activity among their preschoolers. Applied Physiology, Nutrition, and Metabolism, 33(2), 338-346. https://doi.org/10.1139/H07-195

Epstein, J. L. (2010). School/Family/Community Partnerships: Caring for the children we share. Phi Delta Kappan , 92(3), 81-96. https://doi.org/10.1177/003172171009200326

Forry, N.D., Moodie, S., Simkin, S. \& Rothenberg, L. (2011). Family-Provider Relationships: A Multidisciplinary Review of High Quality Practices and Associations with Family, Child, and Provider Outcomes, Issue Brief OPRE 2011-26a. Washington, DC: Office of Planning, Research and Evaluation, Administration for Children and Families, U.S. Department of Health and Human Services.

Fox, M. K., Gearan, E., Cannon, J., Briefel, R., Deming, D. M., Eldridge, A. L., \& Reidy, K. C. (2016). Usual food intakes of 2- and 3-year old U.S. children are not consistent with dietary guidelines. BMC Nutrition, 2(1), 67. https://doi.org/10.1186/s40795-016-0106-2 
Gardner, B., Whittington, C., McAteer, J., Eccles, M. P., \& Michie, S. (2010). Using theory to synthesise evidence from behaviour change interventions: The example of audit and feedback. Social Science \& Medicine, 70(10), 1618-1625.

https://doi.org/10.1016/j.socscimed.2010.01.039

Guest, G., Bunce, A., \& Johnson, L. (2006). How many interviews are enough? Field Methods, 18(1), 59-82. https://doi.org/10.1177/1525822X05279903

Halgunseth, L. C., Peterson, A., Stark, D.R., \& Moodie S. (2009). Family Engagement, Diverse Families, and Early Childhood Education Programs: An Integrated Review of the Literature. National Institute for Early Education Research. http://nieer.org/wpcontent/uploads/2011/09/EDF_Literature20Review.pdf

Hennink-Kaminski, H., Vaughn, A. E., Hales, D., Moore, R. H., Luecking, C. T., \& Ward, D. S. (2018). Parent and child care provider partnerships: Protocol for the Healthy Me, Healthy We (HMHW) cluster randomized control trial. Contemporary Clinical Trials, 64, 49-57. https://doi.org/10.1016/J.CCT.2017.11.007

Huynh, A. K., Hamilton, A. B., Farmer, M. M., Bean-Mayberry, B., Stirman, S. W., Moin, T., \& Finley, E. P. (2018). A Pragmatic approach to guide implementation evaluation research: Strategy mapping for complex interventions. Frontiers in Public Health, 6. https://doi.org/10.3389/fpubh.2018.00134

Institute of Medicine. (2000). From Neurons to Neighborhood: The Science of Early Childhood Development. The National Academies Press. https://doi.org/10.17226/9824

Janz, K. F., Dawson, J. D., \& Mahoney, L. T. (2000). Tracking physical fitness and physical activity from childhood to adolescence: the Muscatine study. Medicine \& Science in Sports \& Exercise, 32(7), 1250-1257. 
Jarvis, J. W., Harrington, D. W., \& Manson, H. (2017). Exploring parent-reported barriers to supporting their child's health behaviors: a cross-sectional study. International Journal of Behavioral Nutrition and Physical Activity, 14(1), 77. https://doi.org/10.1186/s12966-017$0508-9$

Jayasuriya, A., Williams, M., Edwards, T., \& Tandon, P. (2016). Parents’ perceptions of preschool activities: exploring outdoor play. Early Education and Development, 27(7), 1004-1017. https://doi.org/10.1080/10409289.2016.1156989

Johnson, S. L., Ramsay, S., Aromstrong Shultz, J., Branen, L. J., \& Fletcher, J. W. (2013). Creating potential for common ground and communication between early childhood program staff and parents about young children's eating. Journal of Nutrition Education and Behavior, 45, 558-570. https://doi.org/10.1016/j.jneb.2013.02.009

Karakuş, M., \& Savaş, A. C. (2012). The effects of parental involvement, trust in parents, trust in students and pupil control ideology on conflict management strategies of early childhood teachers. Educational Sciences: Theory \& Practice, 12(4), 2977-2985.

Kim, K., Porter, T., Atkinson, V., Rui, N., Ramos, M., Brown, E., ... Nord, C. (2015). Family and Provider/Teacher Relationship Quality Measures: Updated User's Manual. OPRE Report 2014-65. Washington, DC: Office of Planning, Research and Evaluation, Administration for Children and Families, U.S. Department of Health and Human Services. Larson, N., Ward, D. S., Neelon, S. B., \& Story, M. (2011). What role can child-care settings play in obesity prevention? A review of the evidence and call for research efforts. Journal of the American Dietetic Association, 111(9), 1343-1362.

https://doi.org/10.1016/j.jada.2011.06.007

Leeman, J., Calancie, L., Hartman, M. A., Escoffery, C. T., Herrmann, A. K., Tague, L. E., ... 
Samuel-Hodge, C. (2015). What strategies are used to build practitioners' capacity to implement community-based interventions and are they effective?: A systematic review. Implementation Science, 10(1). https://doi.org/10.1186/s13012-015-0272-7

Levitt, H. M., Bamberg, M., Creswell, J. W., Frost, D. M., Josselson, R., \& Suárez-Orozco, C. (2018). Journal article reporting standards for qualitative primary, qualitative meta-analytic, and mixed methods research in psychology: The APA Publications and Communications Board task force report. American Psychologist, 73(1), 26-46. https://doi.org/10.1037/amp0000151

Lyn, R., Evers, S., Davis, J., Maalouf, J., \& Griffin, M. (2014). Barriers and supports to implementing a nutrition and physical activity intervention in child care: Directors' perspectives. Journal of Nutrition Education and Behavior, 46(3), 171-180. https://doi.org/10.1016/j.jneb.2013.11.003

McHugh, M. L. (2012). Interrater reliability: The kappa statistic. Biochemia Medica, 22(3), 276282. https://doi.org/10.11613/bm.2012.031

Nilsen, P. (2015). Making sense of implementation theories, models and frameworks. Implementation Science, 10(1), 53. https://doi.org/10.1186/s13012-015-0242-0

Nixon, C. A., Moore, H. J., Douthwaite, W., Gibson, E. L., Vogele, C., Kreichauf, S., ... ToyBox-study group. (2012). Identifying effective behavioural models and behaviour change strategies underpinning preschool- and school-based obesity prevention interventions aimed at 4-6-year-olds: a systematic review. Obesity Reviews, 13(Supplment 1), 106-117. https://doi.org/10.1111/j.1467-789X.2011.00962.x

Palinkas, L. A., Aarons, G. A., Horwitz, S., Chamberlain, P., Hurlburt, M., \& Landsverk, J. (2011). Mixed method designs in implementation research. Administration and Policy in 
Mental Health and Mental Health Services Research, 38(1), 44-53.

https://doi.org/10.1007/s10488-010-0314-z

Palinkas, L. A., Horwitz, S. M., Green, C. A., Wisdom, J. P., Duan, N., \& Hoagwood, K. (2015).

Purposeful sampling for qualitative data collection and analysis in mixed method implementation research. Administration and Policy in Mental Health and Mental Health Services Research, 42(5), 533-544. https://doi.org/10.1007/s10488-013-0528-y

Reedy, C. K., \& McGrath, W. H. (2010). Can you hear me now? Staff-parent communication in child care centres. Early Child Development and Care, 180(3), 347-357.

https://doi.org/10.1080/03004430801908418

Saldaña, J. (2013). The coding manual for qualitative researchers. SAGE Publications.

Savage, J. S., Fisher, J. O., \& Birch, L. L. (2007). Parental influence on eating behavior: conception to adolescence. The Journal of Law, Medicine \& Ethics, 35(1), 22-34. https://doi.org/10.1111/j.1748-720X.2007.00111.x

Slater, A., Bowen, J., Corsini, N., Gardner, C., Golley, R., \& Noakes, M. (2010). Understanding parent concerns about children's diet, activity and weight status: an important step towards effective obesity prevention interventions. Public Health Nutrition, 13(8), 1221-1228. https://doi.org/10.1017/S1368980009992096

Tandon, P. S., Saelens, B. E., \& Copeland, K. A. (2016). A comparison of parent and childcare provider's attitudes and perceptions about preschoolers' physical activity and outdoor time. Child: Care, Health and Development, 43(5), 679-686. https://doi.org/10.1111/cch.12429

Taveras, E. M., LaPelle, N., Gupta, R. S., \& Finkelstein, J. A. (2006). Planning for health promotion in low-income preschool child care settings: Focus groups of parents and child care providers. Ambulatory Pediatrics, 6(6), 342-346. 
https://doi.org/10.1016/j.ambp.2006.07.004

The Consolidated Framework for Implementation Research. (n.d.). Qualitative data. Retrieved March 13, 2019, from https://cfirguide.org/evaluation-design/qualitative-data/

Vaughn, A. E., Bartlett, R., Luecking, C. T., Hennink-Kaminski, H., \& Ward, D. S. (2018). Using a social marketing approach to develop Healthy Me, Healthy We: a nutrition and physical activity intervention in early care and education. Translational Behavioral Medicine, 9(4), 669-681. https://doi.org/10.1093/tbm/iby082

Vaughn, A. E., Studts, C. R., Powell, B. J., Ammerman, A. S., Trogdon, J. G., Curran, G. M., ... Ward, D. S. (2019). The impact of basic vs. enhanced Go NAPSACC on child care centers' healthy eating and physical activity practices: Protocol for a type 3 hybrid effectivenessimplementation cluster-randomized trial. Implementation Science, 14(1), 101. https://doi.org/10.1186/s13012-019-0949-4

Bartholomew, L. K., Parcel, G. S., \& Kok, G. (1998). Intervention mapping: A process for developing theory and evidence-based health education programs. Health Education \& Behavior, 25(5), 545-563. https://doi.org/10.1177/109019819802500502

Beets, M. W., Bornstein, D., Dowda, M., \& Pate, R. R. (2011). Compliance with national guidelines for physical activity in U.S. preschoolers: measurement and interpretation. Pediatrics, 127(4), 658-664. https://doi.org/10.1542/peds.2010-2021

Birch, L., \& Fisher, J. (1998). Development of eating behaviors among children and adolescents. Pediatrics, 101(Supplement 2), 539-549.

Chow, A. F., \& Humbert, L. (2011). Physical activity and nutrition in early years care centres: Barriers and facilitators. Journal of Childhood Studies, 36(1), 26-30. https://doi.org/10.18357/jcs.v36i1.15136 
Corcoran, L., Steinley, K., \& Grady, S. (2016). Early Childhood Program Participation, Results from the National Household Education Surveys Program of 2016 (NCES 2017-101.REV), National Center for Education Statistics, Institute of Education Services, U.S. Department of Education. Washington, DC. Retrieved April 6, 2019 from https://nces.ed.gov/pubs2017/2017101REV.pdf

Creswell, J. W., \& Plano Clark, V. L. (2011). Designing and conducting mixed methods research (3rd ed.). SAGE Publications, Inc.

Damschroder, L. J., Aron, D. C., Keith, R. E., Kirsh, S. R., Alexander, J. A., \& Lowery, J. C. (2009). Fostering implementation of health services research findings into practice: a consolidated framework for advancing implementation science. Implementation Science, 4(1), 50. https://doi.org/10.1186/1748-5908-4-50

Dehar, M.-A., Casswell, S., \& Duignan, P. (1993). Formative and process evaluation of health promotion and disease prevention programs. Evaluation Review, 17(2), 204-220. https://doi.org/10.1177/0193841X9301700205

Dev, D. A., Byrd-Williams, C., Ramsay, S., McBride, B., Srivastava, D., Murriel, A., ... AdachiMejia, A. M. (2017). Engaging parents to promote children's nutrition and health. American Journal of Health Promotion, 31(2), 153-162. https://doi.org/10.1177/0890117116685426

Douglass, A. (2011). Improving family engagement: The organizational context and its influence on partnering with parents in formal child care settings. Early Childhood Research and Practice, $13(2)$.

Epstein, J. L. (2010). School/Family/Community Partnerships: Caring for the children we share. Phi Delta Kappan , 92(3), 81-96. https://doi.org/10.1177/003172171009200326

Forry, N.D., Moodie, S., Simkin, S. \& Rothenberg, L. (2011). Family-Provider Relationships: A 
Multidisciplinary Review of High Quality Practices and Associations with Family, Child, and Provider Outcomes, Issue Brief OPRE 2011-26a. Washington, DC: Office of Planning, Research and Evaluation, Administration for Children and Families, U.S. Department of Health and Human Services.

Fox, M. K., Gearan, E., Cannon, J., Briefel, R., Deming, D. M., Eldridge, A. L., \& Reidy, K. C. (2016). Usual food intakes of 2- and 3-year old U.S. children are not consistent with dietary guidelines. BMC Nutrition, 2(1), 67. https://doi.org/10.1186/s40795-016-0106-2

Gardner, B., Whittington, C., McAteer, J., Eccles, M. P., \& Michie, S. (2010). Using theory to synthesise evidence from behaviour change interventions: The example of audit and feedback. Social Science \& Medicine, 70(10), 1618-1625. https://doi.org/10.1016/j.socscimed.2010.01.039

Guest, G., Bunce, A., \& Johnson, L. (2006). How many interviews are enough? Field Methods, 18(1), 59-82. https://doi.org/10.1177/1525822X05279903

Halgunseth, L. C., Peterson, A., Stark, D.R., \& Moodie S. (2009). Family Engagement, Diverse Families, and Early Childhood Education Programs: An Integrated Review of the Literature. National Institute for Early Education Research. http://nieer.org/wpcontent/uploads/2011/09/EDF_Literature20Review.pdf

Hennink-Kaminski, H., Vaughn, A. E., Hales, D., Moore, R. H., Luecking, C. T., \& Ward, D. S. (2018). Parent and child care provider partnerships: Protocol for the Healthy Me, Healthy We (HMHW) cluster randomized control trial. Contemporary Clinical Trials, 64, 49-57. https://doi.org/10.1016/J.CCT.2017.11.007

Huynh, A. K., Hamilton, A. B., Farmer, M. M., Bean-Mayberry, B., Stirman, S. W., Moin, T., \& Finley, E. P. (2018). A Pragmatic approach to guide implementation evaluation research: 
Strategy mapping for complex interventions. Frontiers in Public Health, 6. https://doi.org/10.3389/fpubh.2018.00134

Institute of Medicine. (2000). From Neurons to Neighborhood: The Science of Early Childhood Development. The National Academies Press. https://doi.org/10.17226/9824

Janz, K. F., Dawson, J. D., \& Mahoney, L. T. (2000). Tracking physical fitness and physical activity from childhood to adolescence: the Muscatine study. Medicine \& Science in Sports \& Exercise, 32(7), 1250-1257.

Jayasuriya, A., Williams, M., Edwards, T., \& Tandon, P. (2016). Parents' perceptions of preschool activities: exploring outdoor play. Early Education and Development, 27(7), 1004-1017. https://doi.org/10.1080/10409289.2016.1156989

Johnson, S. L., Ramsay, S., Aromstrong Shultz, J., Branen, L. J., \& Fletcher, J. W. (2013). Creating potential for common ground and communication between early childhood program staff and parents about young children's eating. Journal of Nutrition Education and Behavior, 45, 558-570. https://doi.org/10.1016/j.jneb.2013.02.009

Karakuş, M., \& Savaş, A. C. (2012). The effects of parental involvement, trust in parents, trust in students and pupil control ideology on conflict management strategies of early childhood teachers. Educational Sciences: Theory \& Practice, 12(4), 2977-2985.

Kim, K., Porter, T., Atkinson, V., Rui, N., Ramos, M., Brown, E., ... Nord, C. (2015). Family and Provider/Teacher Relationship Quality Measures: Updated User's Manual. OPRE Report 2014-65. Washington, DC: Office of Planning, Research and Evaluation, Administration for Children and Families, U.S. Department of Health and Human Services. Larson, N., Ward, D. S., Neelon, S. B., \& Story, M. (2011). What role can child-care settings play in obesity prevention? A review of the evidence and call for research efforts. Journal 
of the American Dietetic Association, 111(9), 1343-1362.

https://doi.org/10.1016/j.jada.2011.06.007

Leeman, J., Calancie, L., Hartman, M. A., Escoffery, C. T., Herrmann, A. K., Tague, L. E., ... Samuel-Hodge, C. (2015). What strategies are used to build practitioners' capacity to implement community-based interventions and are they effective?: A systematic review. Implementation Science, 10(1). https://doi.org/10.1186/s13012-015-0272-7

Levitt, H. M., Bamberg, M., Creswell, J. W., Frost, D. M., Josselson, R., \& Suárez-Orozco, C. (2018). Journal article reporting standards for qualitative primary, qualitative meta-analytic, and mixed methods research in psychology: The APA Publications and Communications Board task force report. American Psychologist, 73(1), 26-46. https://doi.org/10.1037/amp0000151

Lyn, R., Evers, S., Davis, J., Maalouf, J., \& Griffin, M. (2014). Barriers and supports to implementing a nutrition and physical activity intervention in child care: Directors' perspectives. Journal of Nutrition Education and Behavior, 46(3), 171-180. https://doi.org/10.1016/j.jneb.2013.11.003

Nixon, C. A., Moore, H. J., Douthwaite, W., Gibson, E. L., Vogele, C., Kreichauf, S., ... ToyBox-study group. (2012). Identifying effective behavioural models and behaviour change strategies underpinning preschool- and school-based obesity prevention interventions aimed at 4-6-year-olds: a systematic review. Obesity Reviews, 13(Supplment 1), 106-117. https://doi.org/10.1111/j.1467-789X.2011.00962.x

Palinkas, L. A., Aarons, G. A., Horwitz, S., Chamberlain, P., Hurlburt, M., \& Landsverk, J. (2011). Mixed method designs in implementation research. Administration and Policy in Mental Health and Mental Health Services Research, 38(1), 44-53. 
https://doi.org/10.1007/s 10488-010-0314-z

Palinkas, L. A., Horwitz, S. M., Green, C. A., Wisdom, J. P., Duan, N., \& Hoagwood, K. (2015). Purposeful sampling for qualitative data collection and analysis in mixed method implementation research. Administration and Policy in Mental Health and Mental Health Services Research, 42(5), 533-544. https://doi.org/10.1007/s10488-013-0528-y

Reedy, C. K., \& McGrath, W. H. (2010). Can you hear me now? Staff-parent communication in child care centres. Early Child Development and Care, 180(3), 347-357. https://doi.org/10.1080/03004430801908418

Saldaña, J. (2013). The coding manual for qualitative researchers. SAGE Publications.

Savage, J. S., Fisher, J. O., \& Birch, L. L. (2007). Parental influence on eating behavior: conception to adolescence. The Journal of Law, Medicine \& Ethics, 35(1), 22-34. https://doi.org/10.1111/j.1748-720X.2007.00111.x

Slater, A., Bowen, J., Corsini, N., Gardner, C., Golley, R., \& Noakes, M. (2010). Understanding parent concerns about children's diet, activity and weight status: an important step towards effective obesity prevention interventions. Public Health Nutrition, 13(8), 1221-1228. https://doi.org/10.1017/S1368980009992096

Tandon, P. S., Saelens, B. E., \& Copeland, K. A. (2017). A comparison of parent and childcare provider's attitudes and perceptions about preschoolers' physical activity and outdoor time. Child: Care, Health and Development, 43(5), 679-686. https://doi.org/10.1111/cch.12429

Taveras, E. M., LaPelle, N., Gupta, R. S., \& Finkelstein, J. A. (2006). Planning for health promotion in low-income preschool child care settings: Focus groups of parents and child care providers. Ambulatory Pediatrics, 6(6), 342-346. https://doi.org/10.1016/j.ambp.2006.07.004 
The Consolidated Framework for Implementation Research. (n.d.). Qualitative data. Retrieved March 13, 2019, from https://cfirguide.org/evaluation-design/qualitative-data/

Vaughn, A. E., Bartlett, R., Luecking, C. T., Hennink-Kaminski, H., \& Ward, D. S. (2018).

Using a social marketing approach to develop Healthy Me, Healthy We: a nutrition and physical activity intervention in early care and education. Translational Behavioral Medicine, 9(4), 669-681. https://doi.org/10.1093/tbm/iby082

Vaughn, A. E., Studts, C. R., Powell, B. J., Ammerman, A. S., Trogdon, J. G., Curran, G. M., ... Ward, D. S. (2019). The impact of basic vs. enhanced Go NAPSACC on child care centers' healthy eating and physical activity practices: Protocol for a type 3 hybrid effectivenessimplementation cluster-randomized trial. Implementation Science, 14(1), 101. https://doi.org/10.1186/s13012-019-0949-4

Walker, E. M., Mwaria, M., Coppola, N., \& Chen, C. (2014). Improving the replication success of evidence-based interventions: Why a preimplementation phase matters. Journal of Adolescent Health, 54(3 Supplement), S24-S28. https://doi.org/10.1016/j.jadohealth.2013.11.028

Ward, D., Hales, D., Haverly, K., Marks, J., Benjamin, S., Ball, S., Trost, S. (2008). An instrument to assess the obesogenic environment of child care centers. American Journal of Health Behavior, 32(4), 380-386. https://doi.org/10.5993/AJHB.32.4.5

Ward, D. S., Welker, E., Choate, A., Henderson, K. E., Lott, M., Tovar, A., ... Sallis, J. F. (2017). Strength of obesity prevention interventions in early care and education settings: A systematic review. Preventive Medicine, 95(Supplement), S37-S52. https://doi.org/10.1016/j.ypmed.2016.09.033

Wensing, M., \& Grol, R. (2005). Observational evaluation of implementation strategies. In R. 
Grol, M. Wensing, \& M. Eccles (Eds.), Improving patient care: The implementation of change in clinical practice (pp. 248-255). https://doi.org/10.1002/9781118525975.ch21

Yin, R. K. (2009). Case study research: design and methods (4th ed.). SAGE Publications, Inc.

Zecevic, C. A., Tremblay, L., Lovsin, T., \& Michel, L. (2010). Parental influence on young children's physical activity. International Journal of Pediatrics, 2010, 468526.

https://doi.org/10.1155/2010/468526 
Table 1. Overview of indicator of parent engagement with the Healthy Me, Healthy We (HMHW) campaign

\begin{tabular}{|c|c|c|c|c|c|c|}
\hline Measure & Data Source & Timepoint(s) & Content & Sample Item & $\begin{array}{l}\text { Number } \\
\text { of Items }\end{array}$ & Scoring \\
\hline \multirow[t]{2}{*}{$\begin{array}{l}\text { Environment and } \\
\text { Policy } \\
\text { Assessment and } \\
\text { Observation } \\
\text { document review } \\
\text { (Ward et al., } \\
\text { 2008) }\end{array}$} & Research team & $\begin{array}{l}\text { Prior to HMHW } \\
\text { campaign }\end{array}$ & $\begin{array}{l}\text { Policies and } \\
\text { structured practices } \\
\text { related to parent } \\
\text { engagement around } \\
\text { nutrition, physical } \\
\text { activity, screen time, } \\
\text { and outdoor play and }\end{array}$ & $\begin{array}{l}\text { Documentation of } \\
\text { nutrition or } \\
\text { physical activity } \\
\text { education offered } \\
\text { to parents in the } \\
\text { past year }\end{array}$ & 2 & No (0), Yes (1) \\
\hline & & & learning & $\begin{array}{l}\text { Policy about } \\
\text { guidelines for } \\
\text { families about food } \\
\text { brought in for } \\
\text { holidays and } \\
\text { celebrations }\end{array}$ & 5 & $\begin{array}{l}\text { 3-point scale: } \\
\text { topic not mentioned }(0) \text {, } \\
\text { topic is fully covered (2) }\end{array}$ \\
\hline \multirow[t]{2}{*}{$\begin{array}{l}\text { Structured } \\
\text { interview }\end{array}$} & Directors & $\begin{array}{l}\text { Months } 2 \text { and } 6 \\
\text { technical } \\
\text { assistance visits }\end{array}$ & $\begin{array}{l}\text { Implementation of } \\
\text { the campaign: } \\
\text { Carrying out HMHW }\end{array}$ & $\begin{array}{l}\text { Felt strength of } \\
\text { doing HMHW is } \\
\text { that it connects to } \\
\text { the home }\end{array}$ & 2 & No (0), Yes (1) \\
\hline & & & $\begin{array}{l}\text { communication } \\
\text { between center and } \\
\text { home; parent } \\
\text { participation and } \\
\text { feedback }\end{array}$ & $\begin{array}{l}\text { Expressed } \\
\text { difficulty in } \\
\text { communication } \\
\text { between teachers } \\
\text { and parents or } \\
\text { parent participation }\end{array}$ & 7 & $\begin{array}{l}\text { 3-point scale: } \\
\text { A lot of difficulty }(0) \text {, } \\
\text { No difficulty }(2)\end{array}$ \\
\hline $\begin{array}{l}\text { Structured } \\
\text { interview }\end{array}$ & Teachers & $\begin{array}{l}\text { Months } 2 \text { and } 6 \\
\text { technical } \\
\text { assistance visits }\end{array}$ & $\begin{array}{l}\text { Implementation of } \\
\text { the campaign: } \\
\text { Carrying out HMHW } \\
\text { in classroom; } \\
\text { communication with } \\
\text { parents; parent } \\
\text { participation and } \\
\text { feedback }\end{array}$ & $\begin{array}{l}\text { Expressed } \\
\text { difficulty carrying } \\
\text { out HMHW }\end{array}$ & 6 & $\begin{array}{l}\text { 3-point scale: } \\
\text { A lot of difficulty }(0) \text {, } \\
\text { No difficulty }(2)\end{array}$ \\
\hline
\end{tabular}


BARRIERS AND FACILITATORS OF PARENT ENGAGEMENT

\begin{tabular}{|c|c|c|c|c|c|c|}
\hline \multirow[t]{4}{*}{ Survey } & \multirow[t]{4}{*}{ Parents } & \multirow[t]{4}{*}{$\begin{array}{l}\text { End of HMHW } \\
\text { campaign }\end{array}$} & $\begin{array}{l}\text { Exposure to } \\
\text { intervention } \\
\text { materials }\end{array}$ & $\begin{array}{l}\text { Received Unit } 1 \\
\text { Family Guide }\end{array}$ & 11 & $\begin{array}{c}\text { 3-point scale: } \\
\text { No (0), Unsure (1), } \\
\text { Yes (2) }\end{array}$ \\
\hline & & & Dose received & $\begin{array}{l}\text { Number of home } \\
\text { activities tried }\end{array}$ & 2 & $\begin{array}{c}\text { 6-point scale: } \\
\text { Unsure }(0), 25 \text { or more } \\
(5)\end{array}$ \\
\hline & & & $\begin{array}{l}\text { Enactment: } \\
\text { Application of } \\
\text { knowledge and skills } \\
\text { promoted by HMHW }\end{array}$ & $\begin{array}{l}\text { I tried "Just Try It" } \\
\text { suggestions }\end{array}$ & 5 & $\begin{array}{l}\text { 2-point scale: } \\
\text { Disagree/neutral or no } \\
\text { (0), Agree or yes (1) }\end{array}$ \\
\hline & & & $\begin{array}{l}\text { Understanding of } \\
\text { program and role }\end{array}$ & $\begin{array}{l}\text { I understand the } \\
\text { HMHW program }\end{array}$ & 2 & $\begin{array}{l}\text { 5-point scale: } \\
\text { Very poorly }(0) \text {, } \\
\text { Very well }(4)\end{array}$ \\
\hline Survey & $\begin{array}{l}\text { Study } \\
\text { Interventionist }\end{array}$ & $\begin{array}{l}\text { End of HMHW } \\
\text { campaign }\end{array}$ & $\begin{array}{l}\text { Organizational } \\
\text { context: Work load, } \\
\text { turnover, } \\
\text { communication } \\
\text { within and outside of } \\
\text { center }\end{array}$ & $\begin{array}{l}\text { Staff aware of and } \\
\text { supported each } \\
\text { other's efforts to } \\
\text { deliver HMHW and } \\
\text { connect with } \\
\text { parents }\end{array}$ & 11 & $\begin{array}{l}\text { 5-point scale: } \\
\text { Not at all (1), Fully (5) }\end{array}$ \\
\hline
\end{tabular}


Table 2. Characteristics of early care and education centers representing low and high parent engagement with the Healthy Me, Healthy We campaign $(\mathrm{n}=7)^{\mathrm{a}}$

\begin{tabular}{|c|c|c|}
\hline Criteria & $\begin{array}{c}\text { Low Parent } \\
\text { Engagement } \\
(n=3)\end{array}$ & $\begin{array}{c}\text { High Parent } \\
\text { Engagement } \\
(n=4)\end{array}$ \\
\hline Parent engagement score, mean (range) & $53(47-57)$ & $89(82-104)$ \\
\hline Accepts child care subsidies & 3 & 4 \\
\hline $\begin{array}{l}\text { Participates in the Child and Adult Care } \\
\text { Food Program }\end{array}$ & 3 & 4 \\
\hline $\begin{array}{l}\text { Accredited by the National Association } \\
\text { for the Education of Young Children }{ }^{b}\end{array}$ & 1 & 0 \\
\hline \multicolumn{3}{|l|}{ Other program affiliations ${ }^{\mathrm{c}}$} \\
\hline NC Pre- $\mathrm{K}^{\mathrm{d}}$ or other prekindergarten & 1 & 2 \\
\hline Head Start and/or Early Head Start & 1 & 2 \\
\hline Faith-based & 1 & 1 \\
\hline Use health promotion curriculum & 1 & 3 \\
\hline Total child enrollment, mean (range) & $99(54-125)$ & $80(30-118)$ \\
\hline $\begin{array}{l}\text { Weekly enrollment fees for 3-4-year-old } \\
\text { children, mean }\end{array}$ & $\$ 108$ & $\$ 114$ \\
\hline
\end{tabular}

${ }^{a}$ All data presented as absolute numbers unless otherwise indicated

${ }^{\mathrm{b}}$ Data missing for 1 high engagement center

${ }^{\mathrm{c}}$ Could select all that apply

${ }^{\mathrm{d}}$ North Carolina Prekindergarten program 
Table 3. Demographic characteristics of early care and education directors $(n=7)$, teachers $(n=9)$, and parents $(\mathrm{n}=12)$ representing low and high parent engagement with the Healthy Me, Healthy We campaign ${ }^{\mathrm{a}}$

\begin{tabular}{|c|c|c|c|c|c|c|}
\hline \multirow[b]{2}{*}{ Characteristics } & \multicolumn{3}{|c|}{ Low Parent Engagement } & \multicolumn{3}{|c|}{ High Parent Engagement } \\
\hline & $\begin{array}{c}\text { Directors } \\
(n=3)\end{array}$ & $\begin{array}{c}\text { Teachers } \\
(n=5)\end{array}$ & $\begin{array}{c}\text { Parents } \\
(n=6)\end{array}$ & $\begin{array}{c}\text { Directors } \\
(n=4)\end{array}$ & $\begin{array}{c}\text { Teachers } \\
(n=4)\end{array}$ & $\begin{array}{c}\text { Parents } \\
(n=6)\end{array}$ \\
\hline Sex, female & 3 & 5 & 5 & 4 & 4 & 6 \\
\hline Age, years $\left(\right.$ mean $\left.\pm \mathrm{sd}^{\mathrm{b}}\right)$ & $45 \pm 13.6$ & $32 \pm 3.6$ & $36 \pm 8.4$ & $56 \pm 9.0$ & $46 \pm 10.9$ & $30 \pm 6.2$ \\
\hline \multicolumn{7}{|l|}{ Race } \\
\hline African American or black & 3 & 3 & 6 & 3 & 4 & 5 \\
\hline White & - & 2 & - & 1 & - & 1 \\
\hline Hispanic or Latino & - & - & - & - & - & 1 \\
\hline \multicolumn{7}{|l|}{ Highest level of education completed } \\
\hline Some college or lower & 1 & 2 & 3 & - & 2 & 4 \\
\hline Associate degree & - & 1 & 2 & 1 & 2 & - \\
\hline College degree & - & 2 & 1 & 2 & - & - \\
\hline Masters/doctoral degree & 2 & - & - & 1 & - & 2 \\
\hline \multicolumn{7}{|l|}{ Annual family household income } \\
\hline Less than $\$ 30,000$ & 1 & 4 & 1 & - & 1 & 2 \\
\hline$\$ 30,000-\$ 59,999$ & 1 & 1 & 1 & 2 & - & 2 \\
\hline More than $\$ 60,000$ & 1 & - & 1 & 1 & 1 & 1 \\
\hline Prefer not to answer & - & - & 3 & 1 & 2 & 1 \\
\hline Time at center, years (mean $\pm \mathrm{sd})$ & $9 \pm 5.5$ & $1 \pm 0.9$ & $4 \pm 3.3$ & $5 \pm 6.2$ & $9 \pm 9.0$ & $5 \pm 6.5$ \\
\hline Work experience, years (mean $\pm \mathrm{sd}$ ) & $14 \pm 7.8$ & $5 \pm 4.3$ & & $16 \pm 10.6$ & $12 \pm 7.2$ & \\
\hline
\end{tabular}

${ }^{a}$ All data presented as absolute numbers unless otherwise indicated

${ }^{\mathrm{b}}$ sd: standard deviation 
Table 4. Prominent differences between low and high parent engagement centers that serve as barriers or facilitators of parent engagement

\begin{tabular}{|c|c|c|}
\hline $\begin{array}{l}\text { Barrier/Facilitator } \\
\text { (Framework - } \\
\text { Construct) }\end{array}$ & Low Parent Engagement & High Parent Engagement \\
\hline $\begin{array}{l}\text { Center culture } \\
\left(C F I R^{a}-\text { culture }\right)\end{array}$ & $\begin{array}{l}\text { "Reach the entire family" More } \\
\text { focus on doing things for the } \\
\text { parents rather than with the parents }\end{array}$ & $\begin{array}{l}\text { "Connected in a school family" } \\
\text { Strong sense of promoting } \\
\text { collaboration with parents }\end{array}$ \\
\hline $\begin{array}{l}\text { Internal } \\
\text { communication } \\
\text { (CFIR-networks } \\
\text { \& communication) }\end{array}$ & $\begin{array}{l}\text { “More amongst each other" } \\
\text { Parents perceive breakdown in } \\
\text { communication amongst staff } \\
\text { limits the information they receive }\end{array}$ & $\begin{array}{l}\text { "Always in the know" Work flow } \\
\text { design supports communication } \\
\text { about children amongst staff that is } \\
\text { then passed along to parents }\end{array}$ \\
\hline $\begin{array}{l}\text { Communication } \\
\text { across caregivers } \\
\text { (Epstein's }{ }^{b}- \\
\text { communicating) }\end{array}$ & $\begin{array}{l}\text { “I will say we didn't ask” } \\
\text { Emphasis on one-way delivery of } \\
\text { information and less on inviting to } \\
\text { participate or soliciting feedback }\end{array}$ & $\begin{array}{l}\text { "We sure would like to have you" } \\
\text { Efforts to promote two-way } \\
\text { communication include invitations } \\
\text { to be involved or provide feedback }\end{array}$ \\
\hline $\begin{array}{l}\text { Supporting } \\
\text { healthy habits at } \\
\text { home } \\
\text { (Epstein's - } \\
\text { parenting) }\end{array}$ & $\begin{array}{l}\text { “I don't think we do anything” } \\
\text { Lack of conversation, resources, or } \\
\text { other support for healthy eating } \\
\text { and physical activity }\end{array}$ & $\begin{array}{l}\text { "So that they can do better" Parents } \\
\text { received encouragement, } \\
\text { conversations, resources, and } \\
\text { activities to support healthy eating } \\
\text { and physical activity }\end{array}$ \\
\hline $\begin{array}{l}\text { Family-specific } \\
\text { knowledge } \\
\text { (CFIR - knowledge } \\
\text { and beliefs) }\end{array}$ & $\begin{array}{l}\text { "It's like a challenge all the time" } \\
\text { Providers concentrate on soliciting } \\
\text { information solely about, or even } \\
\text { from, the children }\end{array}$ & $\begin{array}{l}\text { "Families are their primary } \\
\text { influence" Providers get to know } \\
\text { families and tailor interactions to } \\
\text { their specific culture and context }\end{array}$ \\
\hline $\begin{array}{l}\text { Providers' } \\
\text { attitudes } \\
\text { (CFIR - other } \\
\text { personal attributes) }\end{array}$ & $\begin{array}{l}\text { “It's still not working” Failed } \\
\text { attempts to get parents involved } \\
\text { leave providers feeling } \\
\text { discouraged and less interested or } \\
\text { willing to try again }\end{array}$ & $\begin{array}{l}\text { “Think outside the box" Instead of } \\
\text { blaming parents for busy lifestyles, } \\
\text { providers work to identify novel } \\
\text { ways that meet needs of family unit }\end{array}$ \\
\hline
\end{tabular}

${ }^{a}$ CFIR: Consolidated Framework for Implementation Research (Damschroder et al., 2009)

${ }^{\mathrm{b}}$ School-Family-Community Partnerships framework (Epstein, 2010) 